\title{
Remarkable Versatility of Silane/Iodonium Salt as Redox Free Radical, Cationic and PhotoPolymerization Initiators
}

\author{
Dengxia Wang ${ }^{1,2,3}$, Florian Szillat, ${ }^{4}$ Jean Pierre Fouassier ${ }^{1}$, Jacques Lalevée ${ }^{1,2 *}$ \\ ${ }^{1}$ Université de Haute-Alsace, CNRS, IS2M UMR 7361, F-68100 Mulhouse, France \\ ${ }^{2}$ Université de Strasbourg, France
}

${ }^{3}$ Shandong Institute of Nonmetallic Materials, Jinan, 250031, China

${ }^{4}$ Dentsply Sirona, De-Trey-Straße 1, Konstanz, Germany

1. Silanes Used in this Work and Previous Works. All the silanes were selected with high purity and used as received (Chart S1). Methyldiphenylsilane (MDPS), Dimethylphenylsilane (DMPS), Triphenylsilane (TPS), Methyltriphenylsilane (MTPS) and Methoxydimethylphenylsilane (MODMPS) were purchased from Alfa Aesar. Phenylsilane (PS), Diphenylsilane (DPS), 1,1,2,2-Tetraphenyldisilane (TPDS), 1,4-Bisdimethylsilylbenzene (BDMSB), tris(trimethylsilyl)silane (TTMSS), were purchased from TCI.

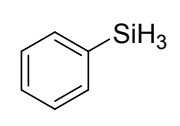

PS<smiles>C[Si](c1ccccc1)(c1ccccc1)c1ccccc1</smiles>

MTPS<smiles>c1ccc([SiH2]c2ccccc2)cc1</smiles>

DPS

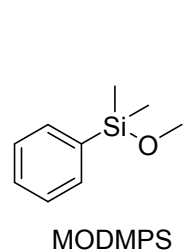

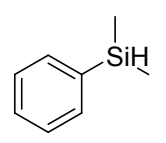

DMPS<smiles>c1ccc([SiH](c2ccccc2)c2ccccc2)cc1</smiles>

TPDS<smiles>C[Si](I)c1ccccc1</smiles>

MDPS

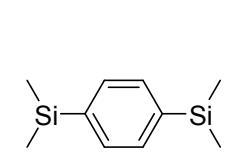

BDMSB

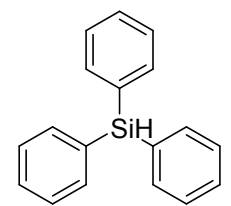

TPS<smiles>C[Si](C)(C)[SiH2][Si](C)(C)C</smiles><smiles>C[Si](C)(C)C</smiles>

TTMSS

Chart S1. Chemical structures of silanes.

2. Preparation of the Cartridges in the Two-component Systems. All redox formulations were prepared from the bulk resins in two separated cartridges: a first cartridge 
(cartridge 1) with the silane and the other one (cartridge 2) containing the iodonium salt (Iod)

(Figure S1B). A 1:1 Sulzer mixpac mixer was used to mix the cartridges together at the beginning of each polymerization experiment. All polymerization experiments will be performed under mild conditions: at room temperature (RT) $\left(21-23{ }^{\circ} \mathrm{C}\right)$ and under air.

\section{Initiating Effect: Comparison of Different Silanes for Resin 1 at Room}

\section{Temperature.}
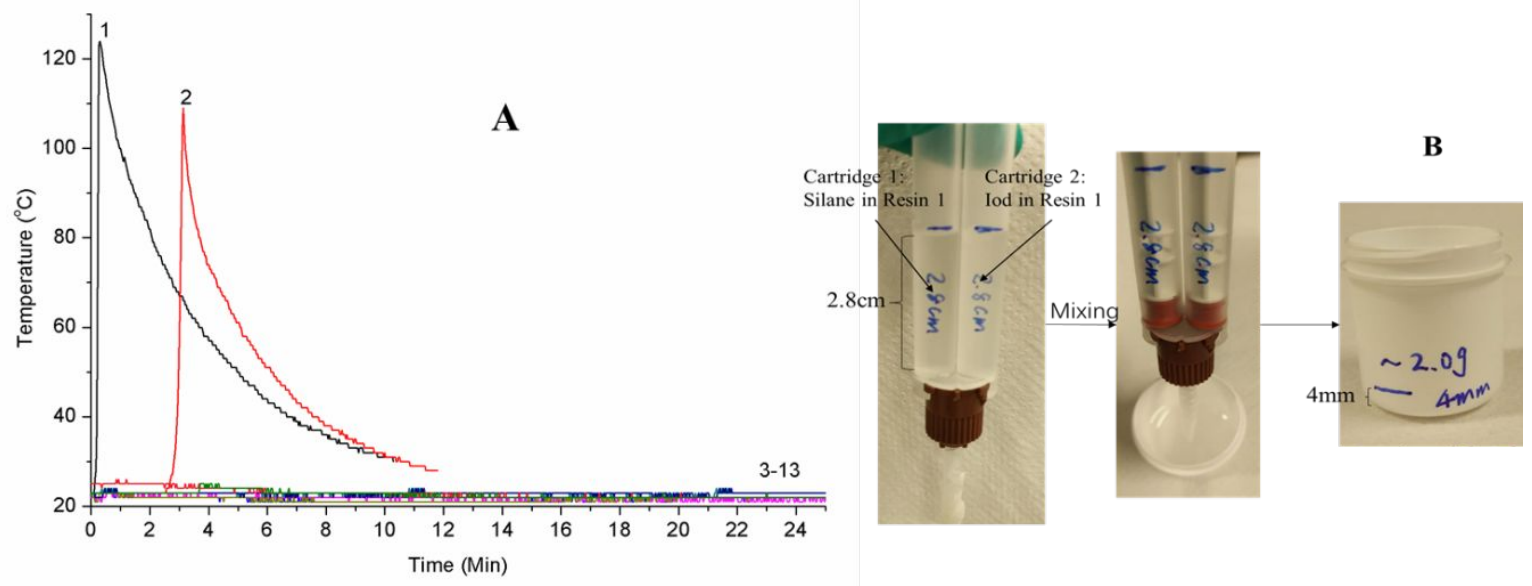

Figure S1. A: Optical pyrometric measurements (sample T $\left({ }^{\circ} \mathrm{C}\right)$ vs time) under air for Resin 1 in presence of different redox initiating systems (RIS): (1) $0.3 \mathrm{wt} \% \mathrm{PS}+0.3 \mathrm{wt} \%$ Iod; (2) 0.5 wt \% DPS + $0.5 \mathrm{wt} \%$ Iod; (3) $1.0 \mathrm{wt} \%$ DMPS + $1.0 \mathrm{wt} \%$ Iod; (4) $1.0 \mathrm{wt} \%$ MDPS $+1.0 \mathrm{wt}$ \% Iod; (5) $1.0 \mathrm{wt} \%$ TPS + $1.0 \mathrm{wt} \%$ Iod; (6) $1.0 \mathrm{wt} \%$ MTPS + $1.0 \mathrm{wt} \%$ Iod; (7) $1.0 \mathrm{wt} \%$ MODMPS + $1.0 \mathrm{wt} \%$ Iod; (8) $1.0 \mathrm{wt} \%$ TPDPS + $1.0 \mathrm{wt} \%$ Iod; (9) $1.0 \mathrm{wt} \%$ BDMSB +1.0 wt \% Iod; (10) $1.0 \mathrm{wt} \%$ TTMSS + $1.0 \mathrm{wt} \%$ Iod; (11) PS alone; (12) DPS alone; (13) Iod alone; $4 \mathrm{~mm}$ thick samples after mixing. B: Picture of mixing method of silane and Iod for the optical pyrometric measurements (see also the experimental part).

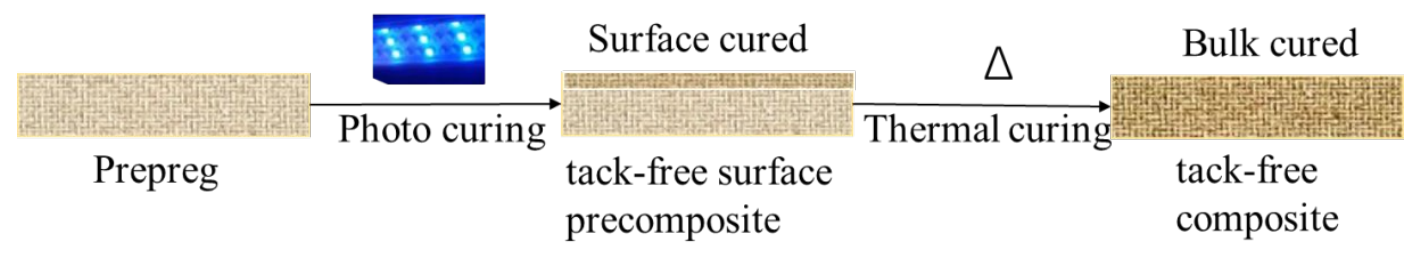

Figure S2. Designed concept diagram for photo/thermal dual curing method of composite. 


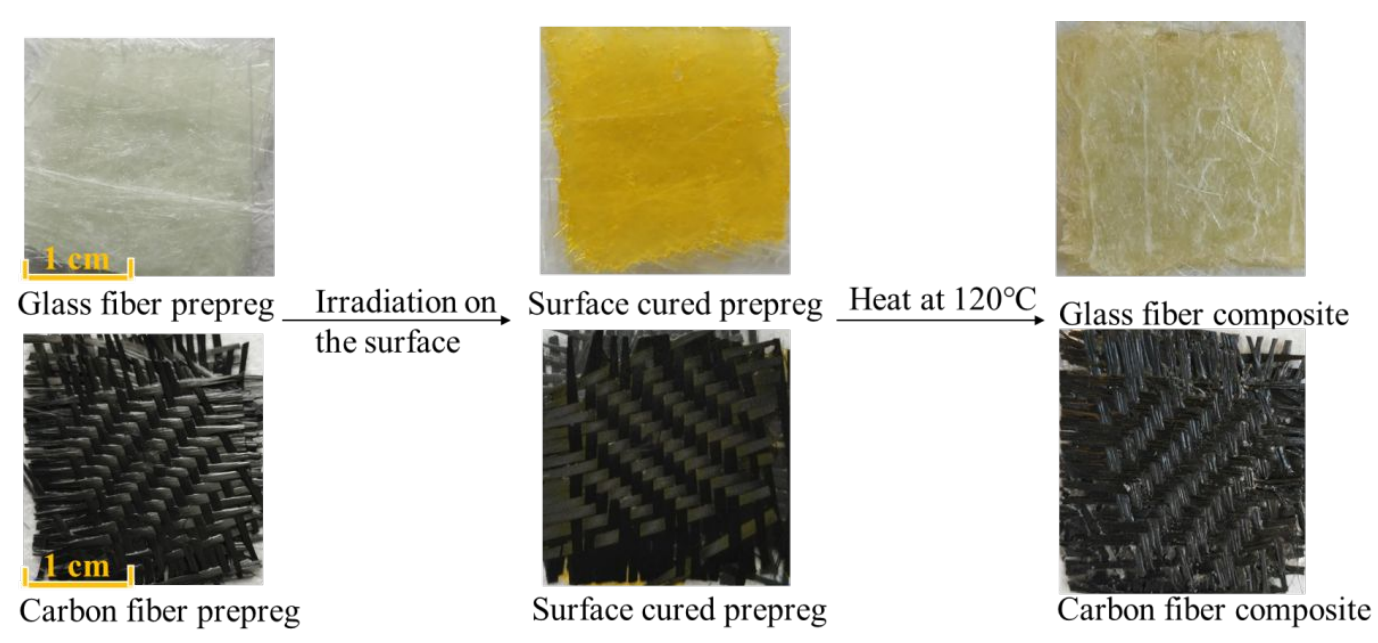

Figure S3. Macrotopography of fabric prepregs, surface cured prepregs and composites and the process of composite curing. Access to prepregs using: $2.0 \mathrm{wt} \% \mathrm{DPS} / 2.0 \mathrm{wt} \% \mathrm{Iod} / 2.0 \mathrm{wt} \%$ 2-ITX in 50/50 (w/w) Resin 3/glass (or carbon) fiber. Access to surface cured prepregs by photocuring using a LED@395 nm (4 W/cm²) (conveyor 3 passes). Access to composites heated at $150^{\circ} \mathrm{C}$ for $2 \mathrm{~h}$. 